\title{
Meditation Matters: Replies to the Anti-McMindfulness Bandwagon!
}

\begin{abstract}
Certain scholars and intellectuals - for example, Slavoj Žižek, Owen Flanagan, Evan Thompson, Gilbert Ryle, Robert Nozick, Allen Ginsberg, Ron Purser, David Loy, Robert Sharf, David Forbes, Suzanne Moore, and others - have joined the bandwagon to criticize meditation, or more specifically, mindfulness, the increasingly popular, originally Buddhist form of meditation, the cultural explosion of interest in which Purser and Loy have cleverly described with their neologism "McMindfulness." I address four types of objections these thinkers have made, some independently: meditation (a) is incoherent or ineffective, (b) fails to attempt to try to change the world, (c) is not really as important to Buddhism as Westerners seem to think it is, as evidenced by the few actually serious practitioners to be found in Buddhism, and (d) ought not to be separated from its Buddhist ethical framework. In rebutting all four claims, I address some on their own terms, but part of my strategy is to put them in dialogue with each other so that they may refute each other.

I argue in defense of meditation. Many and diverse kinds of objections have been leveled against meditation, but I focus only on some representative ones thought to be compelling. Some of the objections are rather informal, while others are philosophically technical; my responses will vary in kind, but even my responses to the technical philosophical objections ought to be comprehensible to non-philosophers. Some objections to meditation predate its being all the rage, as some have described its recent popularity, but most of them are based on its recent popularity. I defend meditation against both sorts of objections.
\end{abstract}

\section{Moore $^{1}$}

For example, an article appeared in the Guardian very clearly exhibiting one of the very positions I am targeting here. "Mindfulness Is All about Self-Help. It Does Nothing to Change an Unjust World," by Suzanne Moore, ${ }^{2}$ is essentially a polemic about the many non-unjust-worldchanging shortcomings of mindfulness. As the title reveals, however, this polemic is analogous to the following complaint: "Journalism Is All about Selling News. It Does Nothing to Change an Unjust World."

Somebody, surely, has to report the news, as objectively as possible, which is a distinct task from that of trying to alter what will become the news. Is it really a shortcoming of

\footnotetext{
${ }^{1}$ The writing of this paper was supported in part by a grant from the National Endowment for the Humanities and the NEH Summer Institute that I attended, "Investigating Consciousness: Buddhist and Contemporary Philosophical Perspectives," at the College of Charleston (Summer 2012).

${ }^{2}$ Moore (2014).
} 
journalism that it merely reports on the injustices in the world but makes no concerted efforts to change it? xxIt is no more a shortcoming of journalism that it fails to try to change an unjust world into a just one than it is a shortcoming of sports that they do not try to change an unjust world into a just one, any more than it is a shortcoming of psychotherapy that it fails to try to change an unjust world into a just one, to mention just two more analogies. The list of analogous things about which it is not a shortcoming about those things that they do not try to change an unjust world into a just world includes, but certainly is not exhausted by, the following: interest in or the collection of stamps, interest in or the collection of recipes, interest in or the collection of aquarium fish or related pets, interest in or devoting one's life to understanding and teaching mathematics or linguistics or philosophy of language or aesthetics or medieval literature or Egyptology or semiotics or the Feldenkrais method or cryptology or hermeneutics or aerodynamics or Wittgenstein or gardening, karate, chess, poetry, art, hydraulics, Classical music, Zumba, dentistry, roofing, rolfing, carpentry, wine-making, embroidery, Pilates, hotel management, automotive mechanics, vinyl repair, bicycling, marathons, accounting, skydiving, fishing, deep sea diving, theater, prestidigitation, photography, calligraphy, food trucks, method acting, writing criticisms or defenses about mindfulness - the list goes on indefinitely, but hopefully the absurdity of claims of the form it is a shortcoming of $x$ that $x$ does nothing to attempt to change an unjust world into a just world is by now abundantly clear.

Yes, just as anything in the world can become the object of philosophical inquiry and examination under the right circumstances, even a ham sandwich (why is it, really, that pork is kosher?), so too any item on the list of things above (about which it is no shortcoming that they are not world-changers) could, in principle, play a role in changing the world in some significant way, under certain hypothetical scenarios and, even if not, should be treated as if engagement in it and devotion of one's life to it or a significant amount of one's time and efforts to it matter ethically and thus are subject to inquiry about whether such efforts might be better placed in the Facebook protesting of fracking, of tax laws that benefit the 1\%, or of the situation in Gaza - as if Facebook activism even purports to amount to a world-changing activity. (Indeed, the illusion that Facebook activism, so to speak, counts as activism, might prevent real activism.)

But surely those are all individual choices-for example, whether one ought to repost a political meme (and then have to deal with the obligation to debate with ideological fundamentalists) or watch another episode of Breaking Bad (and release some of the stress of life by entertaining a fantasy) — best made by individuals situated in the embedded spaces in which their skills, wherewithal, economic lives, functional matrices and overall horizons of reasons for action are enmeshed. Each of us must decide for ourselves how much of our lives (and when and how) it is appropriate for us to dedicate to the furtherance of the common good, to the best of our abilities, given our limitations, and how much of our lives are appropriately devoted to our obligations to our own minds and bodies, loved ones, and other circles of commitment expanding outward from the center of our being toward all other sentient beings and the rest of the cosmos. 
Most of my arguments both above and in what follows are arguments by analogy of the form: that doesn't make sense, because that's like this other thing that obviously doesn't make sense. The problem with analogies is that for something to count as one there must be both some elements in common between the two things being compared or else there would be no basis for the comparison, and some elements not in common or else the two things to be compared would actually be one and the same thing. This requirement of a difference between items constituting an analogy opens the door to charges that the items being compared are not properly analogous because some of their features are not shared, not shared sufficiently, or not shared in the right way. To assess whether such a charge of faulty analogy is apt, it is not enough that there be some difference between the items being compared, for, again, that is a requirement of any analogy. Thus, for an analogy to be faulty, an item in the pair of compared items must lack the feature that is the point of the analogy. I have made many analogies here between the complaint that it is a shortcoming of mindfulness that it fails to attempt to change an unjust world into a just world and similar objections of the general form it is a shortcoming of $x$ that $x$ fails to attempt to change an unjust world into a just world, where my list of instances or values of $\mathrm{x}$ is quite long (weight lifting, stamp collecting, Pilates, chess, and so on). Do any of these items constitute faulty analogies?

Before we answer that, note that it is enough if one of them is not faulty. I could examine each analogy to assess whether it is faulty, but logic and considerations of space suggest that I only assess one analogy. Take weightlifting, then, which Ron Purser has suggested might be a faulty analogy. ${ }^{3}$ Here is why I think it is not faulty. Many people practice weight lifting for any or all of the following expected benefits: working out relaxes them, it relieves stress, it supports a form of social bonding, it improves immune functioning, flexibility, bone density, strength, resilience, weight regulation, metabolism, etc. Meditation is practiced by many because it is touted as yielding many of these benefits. Thus, meditation and weightlifting share many motivational factors, making them somewhat analogous, on the one hand. On the other hand, one might object that it is not the case that weightlifting is all the rage, so to speak, like mindfulness is, and thus that there is a disanalogy. But the unshared elements here-one item being all the rage and the other not being all the rage - are irrelevant to the point of the analogy, and that is that it is a shortcoming of $x$ that $x$ fails to attempt to change an unjust world into a just world.

Technically, even the shared elements mentioned here, which may be summarized as expected (personal and interpersonal) improvements associated with motivations for engaging in both cases of $x$ (meditation and weightlifting), are technically irrelevant to the validity of the analogy. For that, all that is needed is that both items are instances of the formula it is a shortcoming of $x$ that $x$ fails to attempt to change an unjust world into a just world. However, the more elements in common in the pair of items that constitute an analogy, the more likely it is to achieve its goal, which is not so much to prove a point as to facilitate understanding by showing how some feature that is not fully transparent in the original case may be seen more readily in the

\footnotetext{
${ }^{3}$ Personal (Facebook) communication (August 8, 2014).
} 
analogous case, which then ought to make that feature more visible in the original case. Analogies are not technical proofs, but guides to understanding. Thus, even an analogy that proves technically faulty on careful analysis might nonetheless guide understanding.

And we can always patch up an analogy that seems faulty on some such technical grounds, by imagining hypothetical conditions to make the two compared cases more analogous. For example, weightlifting does not come to us from a millennia old spiritual tradition the way mindfulness has come to us from Buddhism, so that is a seemingly significant disanalogous element that someone might appeal to in order to deny the point of - and thus dismiss - the analogy. But we could imagine a hypothetically different past, a possible history in which Shaolin Buddhist monks first invented and institutionalized the practice of weightlifting as a form of yogic bodily control (connected with martial arts), which then spread to all of Buddhism, and for various other hypothetically imaginative reasons never took hold in Western society until, like McMindfulness, it was culturally appropriated from Buddhism, studied by neuroscience, applied in the military, Google, grammar schools, and so forth. Then the analogy would be more perfect: traditionalist Buddhist weightlifters could complain about the dangers of becoming muscular and strong outside the Buddhist ethical framework, non-Buddhists could complain that weightlifting (within or outside Buddhism) fails to try to change the world, philosophers could complain that it doesn't really work or amount to anything significant, and Buddhists and other lovers of weightlifting could complain that empirical studies about weightlifting threaten to miss its true meaning, as if strength was really measurably located in the muscles, and so on. ${ }^{4}$

In all the analogous cases at hand (karate, stamp collecting, and so on), none of this really matters anyway, for they seem valid insofar as one may understand that a claim about each of them to the effect that it is a shortcoming of that item that it fails to attempt to change an unjust world into a just world would be either simply false or, if true, only trivially true. Thus, even if it is irrelevant whether a certain mundane or otherwise necessary activity like brushing one's teeth doesn't change the world, it might be arguable that it a shortcoming of any behavior that it fails to attempt to change the world, but then it would be a shortcoming of almost everything we do, other than efforts specifically designed to try to change the world, that they do not involve efforts to change the world. But the sense in which, if this is true at all, would be trivial, for then not only brushing one's teeth, but sleeping, falling in love, earning a living, spending time with one's elderly grandparents, tying one's shoes, and so forth, would all be subject to such alleged shortcomings. But clearly they are not subject to such objections. Reductio ad absurdum!

Ironically, from the perspective of Buddhism, it actually is a shortcoming of almost everything most of us ever do that it is done mindlessly and not as part of an intentional, mindful effort to either become enlightened (directly or indirectly for the benefit of all sentient beings) or

\footnotetext{
${ }^{4}$ Thompson has criticized contemplative neuroscience research for its reductionism in investigating meditation through brain studies, which he sees as analogous to thinking a bird's flight is somehow located in its wings (Heuman 2014).
} 
to directly reduce suffering in all sentient beings. And attaining enlightenment or reducing the suffering of sentient beings is not only one way of changing the world for the better, but from the Buddhist perspective, the most important way. Be that as it may, however, it is not treated as a criticism to be leveled against all unenlightened or non-enlightenment-seeking beings, but rather a fact to guide the enlightenment-seeking being. From the perspective of Buddhism, the best thing anyone can do is make oneself a better being, as nobody can make anyone else a better being - it is hard enough to make oneself a better being. Nothing about this perspective precludes or disinclines Buddhists from compassionate efforts to reduce suffering and to try to make the world a better place. To the contrary, that is the whole point. True, mindfulness extracted from this larger ethical framework is not as intentionally directed toward these ends as it would be within the Buddhist perspective, but serious, most long-term practitioners believe, reasonably, I think, that any emphasis on mindfulness in one's life - no matter what kind of life that is - will naturally foster the blossoming of these imperatives, as evidenced by the parable of the Buddhist thief.

A certain thief, inspired by the Buddhist teaching, asked the Master to accept him as a disciple, but begged to be allowed to continue his life as a thief, insisting he was incorrigible as such. The Master allowed this, advising the thief only to maintain mindful awareness of all his actions while stealing. Three weeks later the man returned, complaining that he could not both steal and maintain full awareness of what he was doing, for while fully aware of all the implications of his actions his compassion for his victims and what his deeds would cause for them prevented him from stealing. ${ }^{5}$

Arguably, this parable illustrates that - contrary to the objection that mindfulness fails to attempt to change an unjust world into a just world - the ubiquitous acceptance of the mindlessness that is ceaselessly forced upon us by all the competing digital demands, sources of information, and related media and other competitive forces in society is precisely what enables the maintenance of the evil status quo. If that is correct, and it seems to me that it makes a lot more sense than the objections against mindfulness do, then we are under a political obligation to put an end to digital multi-tasking, and to take up practices like mindfulness as weapons in our attempt to reclaim ourselves. The mantra of this mindful political imperative might read: Occupy your own consciousness!

It may just be an article of Buddhist faith that meditative skill promotes sensitivity, empathy, compassion, and the like. The conceptual connection between heightened awareness and compassion is not obvious to non-Buddhists, but for Buddhists it is clear that enlightenment entails the dissolution or at least the desolidifying of the self/other distinction, which intuitively eliminates any unwholesome self-centered motivations and thus inherently promotes a disposition toward altruism, but a form of altruism that is not self-effacing, as the enlightened

\footnotetext{
${ }^{5}$ I cannot find an authoritative cite for this tale, but here is one reference: "Stories from around the World: The Thief (Buddhism)," http://mythologystories.wordpress.com/2013/01/09/thief/.
} 
being is also a being that matters. But it arguably begs the question in favor of Buddhism to say that enlightenment entails the dissolution of the self/non-self distinction and thus altruism, for non-Buddhists cannot be expected to take it on faith that the Buddhist's eightfold meditative path actually leads to enlightenment.

However, even if enlightenment is better understood as a limit case than as an actuality, then it does not seem to beg the question to think it is reasonable that long, serious, disciplined, mindfulness practice generates experiential insights into the nature of the self and all mental states as characterized by momentariness or impermanence, impersonality or the interplay of impersonal conditions and factors, and ontological insubstantiality or existential emptiness, which key insights or "marks of existence" together discourage belief in the value of acting on ego-volitional impulses, craving, and clinging, and thus which foster the falling away of selfishness, and thus which at least indirectly promote spontaneous altruism. One need not believe in the literal attainment of nirvana (enlightenment) in order to believe in these things. In this regard, Flanagan seems right in holding that it is enough, philosophically, for purposes of validating the overall Buddhist world view and teaching, that some meditation virtuosos actually instantiate these practices and qualities. Yes, that may suffice, but surely it is no argument against mindfulness being or becoming all the rage.

Let's return to the masses of hopefully mindful consumers, soldiers, Google employees, and so forth that the phrase "all the rage" denotes. If all a stressed out, underpaid, overworked, over-informed, existentially confused urbanite significantly addicted to social media, constant checking of her cell phone, and marathon television series like Breaking Bad, 24, and Orange Is the New Black can do to try to take care of herself relatively inexpensively is to cultivate a mindfulness practice, who are we to begrudge her because she hasn't joined the Peace Corps or because she cannot afford the professional friendship of her own Gestalt psychotherapist? And just because someone is in the military, works at Google, can afford to wear Prada, or can live off their invested stocks, does that disqualify them from entitlement to enlightenment-fostering practices? Are the otherwise privileged members of $1 \%$ not also entitled to enjoy the fruits of weightlifting or brushing their teeth? Do we really think the movement toward the improvement of society, away from being unjust and toward being more just, is better served by a majority of citizens who are less mindful? This strikes me as a no-brainer, which is why either (a) I must be missing something in all this hoo-hah on the bandwagon against McMindfulness, although I have some ideas about what is behind it, which I will discuss below when I recount my own experiences with the analogous popularization and watering down of yoga, or (b) it simply must be confused. I think it is (b), but I invite others to tutor me about (a), about what I have missed.

Similarly unfair objections could be leveled against what may be caricatured as sustainable-shopping-bag-toting social media activists, whose chanting of their polemicist mantras and performances of the politically correct equivalences of yogic postures in all of their public actions amount to no more than supporting the appearance (to themselves, if nobody else) of insulating them from the guilt of their limousine liberal lifestyles but which, even when 
collectively agglomerated, don't put a small dent in global injustice, but function only to deflect attention away from them and onto the targets of their diatribes. Talk about the pot calling the kettle mindless.

Let us move on to some of the other critiques of meditation. After belaboring the silly objection that it is a shortcoming of meditation that it fails to attempt to change an unjust world into a just world (and I'm afraid we will see further, slightly different iterations of this objection below), addressing a genuinely philosophical objection to meditation ought at least to be intellectually uplifting. I group some of my subsequent rebuttals together, but I review and rebut some of these criticisms one at a time, beginning with the earliest, that of Gilbert Ryle. Although Ryle specifically targeted introspection, and introspection is not necessarily identical with mindfulness or certain other forms of meditation, introspection nonetheless counts as a form of meditative awareness, very close to mindfulness, a standard Buddhist meditation technique.

\section{Ryle}

In his 1949 classic, The Concept of Mind, analytic philosopher Gilbert Ryle argued famously that the concept of introspection is self-refuting. Ryle formulated what many took to be an intuitive if not compelling counter-example to introspection, to be described shortly, but the counterexample was part of his larger, somewhat behaviorist campaign against the Cartesian notion of mind as something that has privileged, immediately transparent access to itself, and the more general idea that the first-personal perspective or subjective stance-which has to do with phenomenology, with what the subject directly experiences, feels, perceives, thinks, and so onis philosophically valid, among other things he called into question. Of course, if the entire firstpersonal perspective is challenged and meditative practices all operate under the assumption of the validity of the first-personal perspective, then meditative practices are thereby called into question by simple implication. Although a rebuttal to his counter-example would count towards a rebuttal of his rejection of the validity of the first-personal perspective, we need only focus on his counter-example and the idea that it allegedly undermines the coherence of meditation. For introspection - inspecting inward and/or watching one's own mental states - is precisely what goes on in various Buddhist and other forms of meditation. ${ }^{6}$ Nevertheless, it should be reiterated that Ryle's counter-example to introspection was intended to illustrate the incoherence of the Cartesian model of mind as immediately accessible and transparent to itself. The point is that he took aim at introspection, most likely only because he thought it illustrated the model of selftransparent mind he rejected. He may not have objected to certain kinds of meditation, if they did not presuppose what he took to be a faulty model of mind.

\footnotetext{
${ }^{6}$ Thompson objects to this characterization of meditation (Heuman 2014), but I do not think my rebuttal to Ryle hinges on anything in his objection.
} 
Ryle, then, interpreted the concept of introspection strictly - arguably, too strictly- to involve the idea of purely observing the contents of one's own mental states without the observation itself having any influence on the mental state being observed; that is, pure introspection must be non-intervening, non-interfering, objective observation. Ryle thought it was intuitive that if the act of observing any mental state influenced that mental state in any way, then it was not truly separate from it, and thus it could not count as genuine introspection. This intuition might be justified as an instance of a more general scientific principle against researchers participating in or otherwise influencing the outcome of their own experiments, in which case if there could not be any such thing as purely non-intervening introspection, then any putative practitioner of introspection would be guilty of something like experimenter bias or nonobjectivity, and thus their claims about their mental states would be tainted and suspect. ${ }^{7}$

Ryle's intuitive counter-example to the idea of introspection, then, involved the idea that if one could actually approximate bringing it about that one was able to take what would putatively amount to an objective observational or impartial witnessing stance towards one's own mental state of, say, rage, then the very act of doing so would - a fortiori, if not a prioriundeniably diminish the intensity, magnitude, and duration of the rage being observed. It would, in other words, interfere with it, in which case if it succeeded in establishing an objective stance in one sense, it would refute itself thereby, in another sense. This counter-example certainly makes sense, at least prima facie. For being able to muster up even the modicum of mental stability or equilibrium that would be necessary for it to be true at all that one was in any sense introspecting one's state of rage, as opposed to being completely (mindlessly) in its grip, it would presumably have to be true that one had to thereby divert a significant amount of mental energy from the rage itself and to simultaneously create some sort of non-rage-like conditions in order to maintain even a fragment of introspective awareness of the rage. I grant this to Ryle.

However, on reflection, even if Ryle's introspecting-rage counter-example does manage to deal a blow to the Cartesian model of self-transparent mind that Ryle targeted with it (which is not necessarily obvious, nor necessarily a concern of ours here), the counter-example fails nonetheless to undermine the version of the idea of introspection that matters for purposes of assessing the efficacy of meditation. First, while it may be interesting or useful if it was possible to have a purely non-intervening form of introspection, it is not obvious that such a nonintervening form of introspection is so centrally definitive of the very concept of introspection that no other concepts are worthy of the name; nor is it obvious that non-intervening introspection is impossible in all cases and in all senses. More importantly, it is not obvious that the only desirable form of introspection is a purely non-intervening one. Indeed, the oppositean intervening form of introspection - may be preferable, and probably is.

\footnotetext{
${ }^{7}$ Of course, if that is correct, then David Hume's and the Buddha's introspective arguments against the reality of the self would collapse.
} 
Of course any attempt to notice or attend to one's mental state necessarily thereby enlarges, so to speak, the resulting mental state to include a self-referential or self-monitoring aspect that was not previously there in the non-introspected mental state, in which case it seems a priori impossible to introspect without intervening - at least in this way - in the mental state that is being introspected. It does not follow, however, that this kind of intervening must always undermine the idea that some form of introspection is occurring, or that it can be objective in some relevant sense. We can describe this kind of intervening as at least involving a kind of change that can be identified merely formally or syntactically, as similar to the way that, say, adding a propositional attitude (e.g., believing, knowing, doubting, remembering, and so forth, are propositional attitudes, that is, attitudes towards propositions) to a proposition (e.g., the claims that the cat is on the mat, or that the earth is round, are propositions) results in at least a formal, grammatical, or syntactical change. Let's call this a syntactic intervention. It is a separate question whether the addition of a particular propositional attitude to a particular proposition alters its content in ways that are more or less substantive than that of what can identified by or as a merely formal syntactical intervention.

For instance, if I assert the proposition, that the cat is on the mat, then that differs grammatically or syntactically from my assertion of my propositional attitude toward that proposition, to the effect that $I$ think it is true that the cat is on the mat. But asserting the truth of a proposition, or my belief in its truth, is roughly equivalent to a redundancy of asserting the proposition: in other words, if I say I think it is true that the cat is on the mat this means about the same thing as my asserting that the cat is on the mat, in which case the syntactical intervention in this case apparently imparts no substantive change to the content of the assertion of the base proposition. Thus, such an innocuous, merely syntactic intervention as this would not jeopardize the validity or objectivity of the base proposition simply by virtue of the fact that it had interfered with it or altered it in some way.

Just as the addition of propositional attitudes to propositions generates a syntactical intervention that merely may be but need not necessarily be substantive or negligible, so too the addition of introspective elements to mental states, for example, those of perceiving, thinking thoughts, and experiencing pain, generates a formal or syntactic intervention that may be but need not necessarily be substantive or negligible. These basic or first-order mental states differ, respectively, from the introspective or higher-order mental states of being aware that one is perceiving, noticing that one is thinking thoughts, or attending to the fact that one is experiencing pain. While these introspective elements may count as propositional attitudes, and thus simply syntactical interventions per se, it might be useful to note that there is a difference between introspective propositional attitudes, such as being aware that, attending to the fact that, being mindful that, and so forth, and non-introspective propositional attitudes, like believing, doubting, suspecting, knowing, and so on. That difference is between metacognitive or otherwise meta-level attitudes and first-order ones, respectively. This distinction will play a role shortly, but the shift from first-order to meta-level mental states, like the shift from propositions to 
propositional attitudes, need not be substantively more than the merely formal, innocuous syntactic difference, but may be more noxious, so to speak, depending on the particulars of individual cases.

Thus, if I am looking at the sunset, my sudden awareness that I am looking at the sunset might count as a spontaneous moment of introspection, and thus it might count as a syntactic or meta-level intervention, but whatever alteration it brings about in my mental state may or may not be relatively negligible, dependent on other factors. Of course, it could lead me to alter my behavior in ways in which the first-order mental state of simply seeing the sunset does not - say, to take a picture of it, to relish in the joy of existence as reflected in it, to compose a haiku (poem) about it, or to call my partner to come look out the window-if the introspective aspect of it was heightened in certain ways. But, alternately, it could just add an otherwise innocuous element of awareness to my perception. (Arguably, even when that meta-awareness alone does not actually manifest in a change, it nonetheless grounds a disposition that enables a range of abilities that then may be acted on, such as the ability to better remember, articulate, and/or act on that perceptual information.) Does it follow that this kind of innocuous syntactic or meta-level intervention necessarily warps that part of the resulting enlarged (because now meta-levelincluding) mental state that was present prior to the enlarging addition of the introspective element? I do not see why that must always be so. Surely, the case of introspecting rage is one that does seem to necessarily alter rage in a substantive way, but rage is not representative of all first-order mental states, as it fails to represent those that are capable of being introspected with negligible degrees of substantive interference, as in the first-order perception of the sunset.

Virtuoso practitioners of mindfulness meditation, one of the central meditative techniques common to most forms of Buddhism, moreover, cultivate an introspective level of skill that might very well reach a threshold of success such that it is sometimes if not increasingly true that they exhibit the ability to impartially observe the arising and passing of momentary mental states - even powerful ones like lust, envy, and hatred — without intervening in them or altering their first-order content whatsoever. We will say more about this later, but to simply assert it in the context of Ryle's claim without some justification would appear to beg the question, so I will say a few words about it for now. First, recall that a merely syntactic or meta-level intervention alone does not necessitate a substantive (as opposed to a purely formal) interference, as has just been argued, rather forcefully. Second, the Buddhist tradition of meditative disciplines is millennia old, and has been perfected by all those generations of meditation masters. Third, the primary prescription of Buddhism is to live a meditative, mindful, or introspective life, so it is not at all surprising that virtuoso meditation practitioners should perfect the art of introspection to the degree that rebuts Ryle's claim even when it comes to many powerful mental states, if not rage itself. (Rage is not only a misrepresentative example when it comes to the issue of noninterfering introspection, but an unfair case se because to be in a state of rage one must have already completely abandoned any effort at self-control or composure, and few other mental states are like this.) More importantly, all attempts to prove that a substantively non-intervening 
form of introspection is possible are technically beside the point when it comes to Buddhist meditation virtuosos.

The reason the possibility of non-intervening introspection is beside the point is that, to the contrary, it is precisely the power of introspective meta-level practices to substantively intervene on the first-order mental states that they are directed at that makes meditation practice an effective tool for self-transformation. A significant part of the Buddhist path is predicated on the Buddha's claim that when he added the meta-level, introspective element of mindfulness to his otherwise non-meta-level meditation practice, which previously consisted simply of onepointedness (focusing his attention on one thing, like staring at a sunset or candle flame), doing so not only changed everything, but led directly to his enlightenment. But he also taught that a significant part of his enlightenment was a function of the insights resulting from the penetration of mindfulness into the dynamics of his own mental states. That is, a blend of non-interfering and interfering elements of meditation seems to have resulted in his enlightenment: insights (about the nature of the self, the impersonal genesis of volition, and so forth) - resulting from what may perhaps be misleadingly described, according to some, as "bare attention," which is in itself noninterfering - manage to alter (interfere with) subsequent perceptions or mental states (constituted by impressions about the insubstantiality of the self, volitions, and so forth). What were earlier seen and believed to be solid, ontologically substantive, independently existing objects separate from a real, substantive, and independent self, once carefully attended to are subsequently perceived as permeable, ontologically insubstantial or empty, only dependently existing phenomena lacking any ontologically independent existence or supporting any substantive self/other boundary.

Much more may be said about this, but it is enough to note that neuroscience research on the minds and brains of long-term practitioners of Buddhist meditation techniques like mindfulness reveals that the transformative effects of this discipline are not only all in the mind, so to speak, but also measurably in the brain: the attention centers associated with introspective practices, for example, are significantly more dense in terms of neural matter and more active in terms of synaptic interactions during the practice (than in control groups). ${ }^{8}$ This sort of thirdpersonal evidence for the efficacy of what may be described as first-personal practices, it should be noted, is something behaviorist folks like Ryle, who favor the third-personal or objective perspective, would have to accept, but it does not necessarily imply, contrary to worries expressed by some, ${ }^{9}$ that this research proves that reductionism (of the mind to just the brain) is being shown thereby. Likewise, similar studies of compassion-generating meditation techniques reveal similarly large and active empathy centers in the brain. ${ }^{10}$ In the past decade alone, hundreds of related findings confirm the efficacy of introspective practices.

\footnotetext{
${ }^{8}$ Lutz, Slagter, Dunne and Davidson (2008).

${ }^{9}$ Heuman (2014).

${ }^{10}$ Lutz, Brefczynski-Lewis, Johnstone, and Davidson (2008).
} 
How does all of this impact our assessment of Ryle's objection? To my lights, these neuroscientific findings do directly support the Rylean point that introspection may interfere substantively in the minds of its practitioners, and significantly in their brains, to boot, on the one hand, but, in the context of the self-transformative purposes of introspective practices in Buddhism, these findings count as powerfully confirming evidence of their efficacy, on the other hand. Thus, these findings show that Ryle's strict interpretation of introspection as purely noninterfering internal observation was needlessly restrictive, if not misleading, insofar as it mischaracterizes what occurs in the most efficacious forms of introspection, in such a way that it appears easily rejected on that ground - in which case Ryle's strict but exaggerated mischaracterization of introspection and subsequent rejection based on that exaggerated notion is a case of the straw man fallacy. Thus, we may set aside Rylean objections to the coherence of the concept of meditation.

The mere act of observing anything arguably affects the nature of the thing observed. ${ }^{11}$ But Buddhist meditation presupposes and embraces this principle, and thus aims to change the mind through introspection. Ryle was one of the first noteworthy Western analytic philosophers to critique the notion of introspection. The next was the noted analytic philosopher, Robert Nozick, who doesn't so much question the coherence of the concept as its efficacy and meaning.

\section{Nozick}

In one of his well-received comprehensive philosophical treatises, Philosophical Explanations, Robert Nozick argued that meditation might amount to a mere damping down of our cognitive apparatus. Nozick uses a thought experiment to pump our intuitions against the idea that there is any merit to meditation techniques and their associated ineffable states, but an analysis of ideas raised in his attack will prove useful to the Buddhist idea that meditation has powerful selftransformative potential. Let us call his argument the "soundless stereo" argument.

Consider a phonograph system as an apparatus of experience.... Now let us do the equivalent of quieting thoughts, namely, removing the record, perhaps also turning off the speakers and the turntable. When only the amplifier is on ..., what is the experience like? We do not know; perhaps infinite.... It would be a mistake to think there is an unusual reality being encountered.... None of the literature I know describes what ... the procedure would produce in the absence of an unusual reality or self, so we don't know whether [it] is a revelation of an unusual reality or self, or instead an artifact of an unusual procedure of experiencing wherein most but not all functions are damped down. (Will this debunking explanation have more difficulty in explaining the surprising and often momentous changes in the people who have the experiences? $)^{12}$

\footnotetext{
${ }^{11}$ Hacking (1983).

12 Nozick (1981), 158-9.
} 
Nozick's intuition pump critiques the meditator's interpreted experience-its background of substantive supramundane metaphysics - but does not necessarily speak to the assumption that the practitioner can disengage conscious awareness from its ordinary functioning, or take it offline, so to speak, from its ordinary engagement and identification with its own contents. $\mathrm{He}$ describes it as a kind of shutting down of the cognitive apparatus, but our analysis of the mechanics of introspective meditation will reveal not that it shuts down the cognitive apparatus, but rather that it interferes with it in a unique and empowering way, as well shall see, by disengaging it from its ordinary sensory-directed functioning. Thus, Nozick's soundless stereo argument does not undermine the point that emerged from our rebuttal to Ryle (about the efficacy of interventionist meditation), on the one hand, and further analysis of this Nozickinspired notion of disengaging the cognitive apparatus from its typical on-line functioning, so to speak, will help for purposes of defending the most general claim of this paper, namely, that meditation matters, on the other hand.

In Buddhist philosophy (and much of the more broad Indian philosophy from which it originally derives), meditation is the path to liberation, construed as freedom from deterministic conative (volitional, motivational, intentional) chains, or karma. Although it is also practiced in other forms of Buddhism, Theravada Buddhists practice vipassana, "insight" or "mindfulness," almost exclusively, which suggests the strategy of mental freedom through insight, based on introspection. I mention this because the mindfulness that is all the rage is derivative of this tradition. Mindfulness occurs throughout but also outside Buddhism as simply the opposite of mindlessness, but the traditional Buddhist practice of mindfulness meditation may be described as the disciplined effort of alert witnessing of what I described above as first-order mental states, which alert witnessing generates higher-order or meta-level mental states. In basic practice, one often first develops some level of concentration by focusing on only one specific object of consciousness, such as the flow of one's breath (or anything). ${ }^{13}$ After proficiency in such "onepointedness" of attention focus is developed, one practices attentiveness to one's entire conscious experience with no attempt to direct awareness, but rather with only the intent to notice or track one's conscious states whatever their content, and wherever they lead on their own, without interference, judgment, or control.

Zen practitioners, for example, also extricate awareness from the first-order stream of occurrent thoughts, emotions, sensations, by simply sitting still and observing the stream of firstorder mental contents. This can create enough distance between the active (content-generating) and the passive (observing) components, though the passive component interferes (as has been shown), which interference is what helps tame the mind and prevent the content-generating component from overcoming the passive observing component. By the meta-level practice of motionlessly witnessing the spontaneous arousal and cessation of first-order mental states without interfering, but just attending carefully to the emergence of intentions, one develops an awareness of the spontaneous and thus impersonal character of their emergence, and thereby

\footnotetext{
${ }^{13}$ Goleman (1988).
} 
gains greater control over the otherwise pre-conscious levers that otherwise mindlessly guide our acts. This is the essence of the Buddhist theory of mental freedom, akin to Freudian and other forms of insight-through-awareness and liberation-through-insight psychologies. ${ }^{14}$

Mind seeing mind - mindfulness, however impure in Ryle's sense - is the key to vipassana. Sustained, keen awareness of psychological state $\mathrm{x}$ is thought to be the best route to insight about x. Vipassana, Zen, and other forms of Buddhist meditation have the common function of training attention by tracking the meditator's mental states. Volitions are 'intentional' in Brentano's sense, in that they have an aboutness to them, as do non-volitional thoughts, sentences, or other meaningful items that are about things. But they are also 'intentional' in the teleological sense that they involve intent, motive, purpose, a goal or end state toward which they point or move. We may thus say that mindfulness meditation cultivates the skills of cognition and intention tracking.

We may compare cognition or intention tracking with Nozick's treatment of truth tracking as a condition on knowledge, ${ }^{15}$ his idea of value tracking as a condition on goodness, ${ }^{16}$ and Wolf's notion of reasons tracking as a condition on moral responsibility. ${ }^{17}$ I will illustrate only one of these notions, as a sample: Nozick's idea that knowledge tracks the truth may be captured in the conditional, if when it is true that $p$ you believe $p$ and when it is false that $p$ you disbelieve $p$, then your belief tracks the truth of $p$. Wolf's and Nozick's notions are metaphorical, since truth, values, and reasons are abstractions that may lack ontological substance (even for non-Buddhist realists), and thus they cannot literally be the objects of inspection or tracking. But intentions certainly exist, and we can concretely inspect and track them, however subtle they are and thus how difficult that may be. And Buddhist practitioners of mindfulness cultivate this ability to virtuoso levels.

In some versions of Buddhist mindfulness of walking or of eating meditations, for example, after first becoming proficient in tracking the physical sensations associated with the physical movements involved, which is no easy task itself, one then shifts attention to focus on the intentions that drive the movements, something so subtle that it is close to impossible to get a handle on except after quite some time in serious practice. The parallels between the utility of Nozick's and Wolf's tracking models and meditation as a form of mental state tracking suggest the utility of the skills of cognition and volition tracking as a condition on self-control and freedom from the bonds of habituated, conditioned, otherwise fairly mindless mental states. For without knowing one's intentions intimately, one cannot help but be pushed or pulled by them.

\footnotetext{
${ }^{14}$ Locke (1690) remarks about stepping back in awareness to gain control over intentions; Hampshire sees awareness of the causes that move one as the key (1975). The Zen or tradition advocates choiceless (non-contracted) awareness, as did Perls (1947), who also called his gestalt psychotherapy "concentration therapy." For a functional analysis of all major forms of meditation, see Goleman (1988). For a deeper analysis of how meditation increases self-regulation, see Repetti (2010).

${ }^{15}$ Nozick (1981), 172-78.

${ }^{16}$ Nozick (1981), 317-31.

${ }^{17}$ Wolf (1990).
} 
Thus, these practices tend to increase the possibility of volitional self-regulation or autonomy. ${ }^{18}$ Practices that increase self-transformation and autonomy are far from ineffective and meaningless, unlike otherwise useless amplifiers in the absence of music, contrary to Nozick's soundless stereo argument.

One-pointedness training may be functionally defined as attention and intention training, for it is designed to train conscious attention, of what one dwells on, thinks about, attends to, is aware of, and so forth, ${ }^{19}$ and these are all objects of one's interests, intentions, and so on. The instrumental utility of the notion of intention training ought to be clear: Attention training fosters intention tracking, and vice versa, and leads to volitional control. Together, intention training and tracking contribute to the formation of higher-order mental states involving an observer (tracker) and controller (trainer) of lower-order mental states: The higher-order tracker may attach a proor con- higher-order label, say, "desirable" or "undesirable," to any spontaneously-arising firstorder mental state, and these evaluative designations facilitate volitional self-regulation. ${ }^{20}$

The proof of all of this is, again, something a behaviorist like Ryle would have to take seriously: observable, measurable behavior. As even Nozick himself admits, serious practitioners of meditation seem transformed by the practice, and they become visibly if not exceedingly altruistic, in ways that stand apart from that of the average good-natured person. To repeat the way he put it at the end of our quote of his attempt at debunking meditation above, Nozick asked:

Will this debunking explanation have more difficulty in explaining the surprising and often momentous changes in the people who have the experiences? ${ }^{21}$

Obviously, the radical behavioral changes that often accompany serious practitioners' claims to transformative experiences are not restricted to increases in the size and activation levels of the neurons associated with empathy, but they also show up rather markedly in their demeanorstranquil, balanced, friendly, generous, nonjudgmental, compassionate, gentle, sensitive,

\footnotetext{
${ }^{18}$ Repetti (2010).

${ }^{19}$ Graziano (2013) argues that consciousness itself may be understood and defined, roughly, as the selectivity of attention, such that we become conscious of those neural goings on that attention selects from among the larger set of cognitive and other mental phenomena encoded in neural networks and interactions, which attentive selection schemas are what generate and constitute conscious experience. If he is at all right, then the attention training that is cultivated in mindfulness and related forms of meditation may actually/literally increase quantities and perhaps also qualities of consciousness, which would confirm some Buddhist theories about its efficacy. Why would only some neural processes loop in on themselves in such a manner or, alternately, if that is all that consciousness is, then why would the brain bother to produce it? I think it is reasonable to think evolution favored those brains that do this because doing so facilitates memory and enables the ability to articulate accounts of what one was thinking and experiencing when one was acting, which abilities would be naturally selected for in social species governed by behavioral norms, such as primates.

${ }^{20}$ They also help construct the sort of volitional/metavolitional hierarchy Harry Frankfurt identified as free will and as constitutive of moral agents or persons (1971). On the convergence between Buddhist volitional regulation and Frankfurt's hierarchical model of free will and personhood, see Repetti (2010).

${ }^{21}$ Nozick (1981), 159.
} 
responsive, and so forth - and in their actions that typically reflect those dispositions, to the point of being enshrined in platitudes.

In fairness to Nozick, it may well be that supramundane elements of Buddhist ideology do often shore up these tendencies in many Buddhists, for example. Belief in the reality of reincarnation and karma, for example, may be easily understood to support the idea that the universe is just, that cosmic justice is built into the nature of things, a belief that is arguably deeply entrenched in certain religious cultures and even lingering in post-religious secular cultures like our own. ${ }^{22}$ This is the sort of belief Nozick has in mind when he suggests that, absent belief in a supramundane reality, meditation might not really amount to more than a mere damping down of one's cognitive apparatus. If one enters into the sort of trance state that Nozick compares with a soundless stereo, feeling a sort of boundless oneness with a universe with builtin cosmic justice, then that could explain significant altruism as a function of some sort of blend of altered states and faith in such beliefs. And that would certainly undermine the idea that meditation is evidentially valid for such individuals, especially if their view that it mattered rested on belief in karma, reincarnation, cosmic justice, and the idea that the trance-like state experienced in meditation was somehow a direct experience of some metaphysically transcendent reality. Undoubtedly, while that is not supposed to be built into the Buddhist experience, it may creep in anyway, and it is explicitly built into the Hindu/yogic experience.

However, absent those supramundane beliefs, we have already shown that meditation matters to self-regulation, and in ways that show up in the attention and empathy centers of the brain. Thus, we have supramundane-belief-independent reasons - non-confirmation-biasinvolving reasons - to think self-transformative behavioral results such as marked altruism stand as valid in their own right. Consequently, we may set aside Nozick's objections to the idea that meditation does not really amount to much. Let us move on to some other objections.

Allen Ginsberg's objection is not that meditation doesn't work or matter, but that it is a kind of distraction that prevents the practitioner from changing the world, a complaint we have already taken apart. And Slavoj Žižek's objection, along similar lines, is that it is worse than that. I address Ginsberg's objection after my treatment of Nozick's objection because Nozick's and Ryle's objections may be grouped together as different forms of the objection that meditation is ineffective or invalid, whereas Ginsberg's objection is the first, historically, of several objections that may be grouped together as different forms of the objection we opened with (about it being a shortcoming of meditation that it is not world-changing), to the effect that meditation has negative social, political, and/or other societal consequences, a kind of objection made most forcefully by Slavoj Žižek, but also by Sharf, Purser and Loy, and Forbes (and Moore, who we already addressed). Let us first address the objections of Ginsberg and Žižek, as their objections more closely resemble each other than do those of Sharf, Purser and Loy, or Forbes.

\footnotetext{
${ }^{22}$ Waller (2013).
} 


\section{Ginsberg and Žižek}

I met Allen Ginsberg through Ram Dass, one of my first and most beloved meditation teachers. Ram Dass spoke on many occasions about how his friend Allen Ginsberg often gave him a hard time, objecting that meditation draws people away from political activism, how he encouraged Ram Dass to get off the meditation cushion, stop retreating from the unjust world, and join in with him for political activism, and so forth. Ram Dass used Allen's objections as a spring board for a number of his remarks in some of his talks, about how enlightened protest was not a contradiction, how it involved protesting unjust actions as opposed to those who perform them, how meditation reduces the tendency to polarize protestors into $u s$ and them, and so forth. Years later, when I contacted Allen (in 1989) and asked him to give a talk on Buddhism at the Brooklyn College Philosophical Society (I was then its president), he agreed, but only after giving me a hard time, this time about wasting my time majoring in analytic philosophy, with its excessive concerns for abstract logical points, scientific and mathematical reasoning, and language analysis, on the same grounds that it failed to engage critically with activist attempts to change the structure of society. (He not only gave a great talk on Buddhism, but he persuaded the rather large turnout of analytic philosophers to take refuge in the three jewels of Buddhism, in Sanskrit, thereby becoming Buddhists, in token if not in spirit.)

In any case, the point of this recounting is that my account of Ginsberg's objections is entirely anecdotal and serves as a sort of priming introduction to the psychoanalyst, philosopher, and social critic Slavoj Žižek's stronger version of the same objection. I'm sure Ginsberg's tendency to speak in this way appears somewhere in print or other recordings of his talks, but nothing hinges on the need for an exact printed proof. I also mention Ginsberg's objections because they are not academic, but pressingly personal, first, and because they are an earlier example of the same sort of objection made by Žižek, who has argued, more forcefully than Ginsberg, that meditation is an opiate for the now secular consumerist masses.

Žižek goes to fairly dramatic lengths to show how Buddhism-inspired but now fundamentally secular Western attitudes of non-judgmentalism, acceptance, passivity, pacifism, tranquility, equilibrium, and the like - the sort of dispositions that are aspired towards as the hopefully attainable consequences of transformative Buddhist meditative practices - fit very conveniently into, and help sustain an unquestioning attitude toward, the status quo of global capitalism, with its vast disparities of wealth and its promulgation of mass consumerism. He suggests that this is the reason mindfulness is all the rage that it now is in so many dimensions of public life and popular culture, ${ }^{23}$ almost as if the behind-the-scenes power brokers and strategic planners of global capitalist neoliberalism invented mindfulness precisely for this purpose- to create the metaphorical equivalent in workers and consumers of better milk-producing, obedient

\footnotetext{
${ }^{23}$ On the claim that it all the rage, see Forbes (2012).
} 
cows. His extremely passionate manner of convinced, indignant expression alone seems to count as an additional argument in favor of his rather conspiratorial interpretation, but, technically, needs to be set aside as an entertaining rhetorical embellishment. In any case, the objection amounts to what I have described as the claim that Buddhist meditation is the new opiate of the now secular masses (in their post-modern withdrawal from the balm of religion), functioning essentially to help maintain the unequal capitalist power structures in place globally. It is a chilling view, one that certainly merits serious reflection.

I will say more about it below. But as I suggested earlier, the objections of Sharf, Purser and Loy, and Forbes are roughly in a league with those of Žižek, though not exactly so or as dramatic. Thus, before further rebutting Žižek's objection (which, I take it, was already rebutted indirectly in my opening rebuttal of Moore's non-world-changing objection), we will entertain their versions of the objection. I will nonetheless first sketch here my answer to Ginsberg and Žižek, and that is that it is a combination of Ram Dass's answer and my own: Ram Dass argued that mindfulness and spiritual growth ought to make one a more enlightened and effective protester, when it is appropriate for one to do so (as opposed to when it is appropriate to spend time in reflection), and I argue that even if what Ginsberg and Žižek worry about is well founded, it is not necessarily the case that meditation must function as a means of pacifying potential activists or as an opiate of the masses. In fact, Purser and Loy, and Forbes, argue that it ought not to function that way, and together with Sharf they all may be said to appeal to the broader Buddhist ethical framework as the remedy to the ill effects of divorcing meditation from that very ethical framework. Odd as it may sound before hearing my reasons, and despite that their appeals to ethics refute Ginsberg and Žižek, I will ultimately reject the idea that the solution lies in the reconciliation of mindfulness with the ethical dimension of Buddhism.

\section{Sharf, Purser and Loy, and Forbes}

Robert Sharf, Ron Purser and David Loy, and David Forbes have objected to the extraction of mindfulness from its Buddhist ethical framework. Sharf has objected to the idea, popular among Westerners increasingly drawn toward mindfulness and other forms of Buddhist meditation, to the effect that they can extract these practices from the ethical and broader philosophical and cultural traditions within which they derive their meaning and value. ${ }^{24}$ He makes a strong case for the idea that the secularized extraction of mindfulness that is becoming increasingly privileged among Westerners who are drawn to it constitutes a serious distortion of the rather narrow social role and institutional function of the practice within Buddhist communities. He also thinks Westerners have literally distorted the techniques, the emphases on various teaching points connected with them, and their overall place and importance in Buddhist life. His

\footnotetext{
${ }^{24}$ Sharf (2012).
} 
objections all have a range of validity, but I reject the idea that the Western embrace of mindfulness is diminished in any way by these putative facts.

In his last point, Sharf actually shares the view we will examine last, Flanagan's and Thompson's, to the effect that meditation is not as central to Buddhism as Westerners have come to think it is. ${ }^{25}$ Before we turn to that view, however, Ron Purser and David Loy have coined the term "McMindfulness" to capture and dramatize the same worries expressed by Sharf, and to highlight the many dimensions of the mindfulness explosion in popular culture, and David Forbes has supported the same concerns, but from what may be described as more of an "integral" philosophical perspective, that is, a perspective that sees the contemplative dimension as only one part of us that needs to be integrated into the many other dimensions of our intrapersonal and interpersonal being - a perspective that seems intuitively correct. All of these thinkers make valid points, and their concerns are all nobly intended to preserve the meaning and value of mindfulness, to protect the venerable contemplative traditions that have delivered it to us, and to ward off potential misunderstandings, distortions, abuses, and applications. I do not take issue with these fine elements of their concerns.

The elements of these views that I do take issue with may be responded to in roughly the same way I responded to Ginsberg's objection, their otherwise important and interesting differences in focus and emphasis notwithstanding. I sketched above what my response to this line of criticism would be: a blend of Ram Dass's and my own, together with my response to calls from some of these very critics to restore the ethical connection to the practices that have become separated from that connection. But let me start with the latter idea first, the idea that the ethical dimension of meditation must be emphasized. While I think this is possibly an acceptable thing to do, and that there might be many great improvements that could result from the teaching of an ethical perspective or framework in connection with the teaching of mindfulness, for example, I do not think it is necessary or necessarily ideal, for a few reasons, despite my generally positive attitude toward the teaching and promotion of ethical values. After all, I do teach ethics classes, but they are part of a philosophy curriculum. (God forbid if ethics became extracted from the philosophy curriculum, popularized, and watered down to the point where everyone found it fashionable to try to justify their actions by casuistry, reasoning from universal principles like the principle that like cases ought to be treated alike, and so forth.)

Contrary to all these worries to the effect that ethics is divorced from mindfulness (as if mindfulness is some power than can wield great harm if not properly harnessed and regulated by ethical beings or norms), mindfulness is intuitively distinct from ethics per se, in its own nature, on the one hand, and that is as it should remain, on the other. As I mentioned in passing early on, mindfulness exists outside the Buddhist tradition simply as the opposite of mindlessness. Paying attention to what one is doing, thinking, feeling, perceiving, or experiencing - these are natural

\footnotetext{
${ }^{25}$ Sharf expressed this aspect of the view in a talk he gave at an NEH Summer Institute that I attended, "Investigating Consciousness: Buddhist and Contemporary Philosophical Perspectives," at the College of Charleston (Summer 2012).
} 
abilities of human beings. The discipline of training oneself to cultivate these abilities - greater degrees of mindfulness - owes much to Buddhism for developing it, but mindfulness is not the province of Buddhism any more than propositional logic or the scientific method are the province of Western philosophy, though anyone who wishes to cultivate their propositional logical skills or their skills in the use of the scientific method owes a historical debt to Western philosophy and science, and may be well served to turn toward them for guidance. Indeed, orthodox Indian philosophers from the Buddha's day could equally object that he divorced the one-pointedness meditation technique from Brahmanism and its important metaphysical conceptions, but Buddhists and others who embrace one-pointedness will celebrate this heretical violation, rightly, as far as I can tell.

As Ginsberg made clear when he criticized me for studying philosophy, he had the same view of analytic philosophy that some of our other critics here have of mindfulness, but these objections are analogous to objecting to science because of its unethical uses or applications. It is not science, analytic philosophy, or mindfulness that are problems. Rather, it is the lack of ethical dispositions, wisdom, and/or virtues that are the problem in all such cases, and those things have nothing to do with philosophy, science, or mindfulness, per se. (This is my somewhat twisted version of turning the objections from those who complain about the divorce of mindfulness from Buddhist ethics on its head.) Ironically, but in pertinent point, mindfulness and related meditation practices, if anything, actually tend to increase ethical sensitivity. ${ }^{26}$ Forbes mentions that some proponents of mindfulness, of which I am one, see mindfulness in this regard as subversively revolutionary, ethical, politically engaging, and all the things these critics worry that it might not be, insofar as it tends to produce dispositions to reflect on everything, toward altruistic sensitivity, and so forth, but he worries that in the hands of such manipulators as the military and Google those tendencies will be downplayed. He may be right, to a certain extent, under certain circumstances. But it is the uses of cell phones, hammers, and just about anything else, as opposed to those objects alone, that are what matter in determining whether they are being put to proper or good use.

On my analysis, it is those uses of meditation under those circumstances (by the military, Google, and so forth) that would be the problem, if they would be a problem at all, not mindfulness itself. If part of your Samurai, Ninja, or Marine training is in the use of mindfulness in order to make you a better warrior, assassin, or soldier, and your martial code is so powerfully psychologically, socially, or otherwise compelling that your mindfulness practice will not likely render that code itself the object of your serious ethical reflection, then there seems intuitively to be a problem with bushido (the martial code), not with practices of disciplining attention, per se. Similar rebuttals may easily be surmised for all the other versions of this objection mentioned above, mutatis mutandis. There is nothing inherently negative about awareness, or the absence of mindlessness. To the contrary, as Socrates noted (and toward which insight he devoted his life,

\footnotetext{
${ }^{26}$ Davis and Thompson (in press).
} 
unto and upon penalty of death), awareness of one's own ignorance contains the very seed of wisdom. And wisdom is probably the greatest virtue, as it inclines one toward all other virtues.

The quite traditional monk Bhikkhu Bodhi addresses the question "whether mindfulness can legitimately be extracted from its traditional context and employed for secular purposes." 27 He holds such applications of mindfulness not only acceptable, but admirable, because they reduce suffering, so he agrees with the tenor of this paper. He does suggest, however, that the reductionist examination of mindfulness associated with what may be described as contemplative neuroscience threatens to distort our understanding of mindfulness, and that for investigators to fully understand it they need to see it as embedded within the religious tradition in which it is rooted. This is a view he shares with Evan Thompson, but I do not think Thompson is against the idea of also researching the phenomenon independently of the religious tradition. ${ }^{28}$ Before we turn to Flanagan's and Thompson's claims, however, there is one more analogy I would like to make about the complaint regarding extracting mindfulness from its larger Buddhist context.

Let me paint a picture of the background for this analogy, which is about the popular divorce of yoga from Hinduism in the West, based on my own personal experience. I have been practicing what I have always thought and continue to think was traditional, Patanjali-based, eight-limbed yoga — what Swami Vivekenanda dubbed "Rajah Yoga" ("kingly yoga") his fancy description for the eight-limbed path of yoga outlined by the ancient sage Patanjali in his classic treatise on the subject, the Yoga Sutras - for as long as I have been practicing meditation, over 40 years now. Indeed, it was my experience of something fantastic, something powerfully mystical and mind-blowing, at the end of my very first yoga session - an unexpected, full-blown out-of-body experience - that led me to take on the practice of meditation as part of my investigation into the spiritual and philosophical dimensions of yoga, for all the texts I could get my hands on recommended meditation as the most powerful key to spiritual growth. I spent the next several years of my life as a very serious yogi (practitioner of yoga and meditation) and a member of an extended set of three overlapping sanghas (spiritual communities) initially defined by three teachers, Ram Dass, Hilda Charlton, and Ma Jaya (then "Joya"), and a universalist blend of mostly Hindu and some Buddhist and other teachings they shared. I was taught the value of traditionalism, and my three teachers never charged us for their services, which included training in yoga, meditation, philosophy, and other forms of esoteric wisdom. I became quite adept at all eight stages of yoga (union, oneness), especially the asanas (postures), pranayama (breathing exercises), dhyāna (attainment of one-pointedness), and samādhi (meditative trance absorption), and soon began to lead a private weekly group of yogis in these practices.

Once just the asanas - which are but one of the eight limbs of traditional yoga - began to be treated as if they were identical to yoga itself, to appear in gyms alongside aerobics classes and the like, and to become commercialized (and rather successful, at that), I must confess I

\footnotetext{
${ }^{27}$ Bodhi (2011), 19.

${ }^{28}$ Thompson (2014).
} 
experienced mixed feelings. On the one hand, I was happy to see some element of yoga finally catching on in the larger culture, even if it was one of the least spiritually transformative elements of the eight-limbed path of yoga that was catching on (the postures), but on the other hand, I was disheartened to see only that element of yoga being treated as the aspect of yoga that would be absorbed into the larger culture, what may be described somewhat diminutively as merely the body-sculpting, stress-relieving, bodily-flexibility-promoting aspect of yoga postures. (It will be helpful to pause here to note that it is no objection against the widespread popularity of asanas-as-yoga that such a practice is not designed to eradicate social injustices, nor against even the totally traditional, full-blown eight-limbed yoga taught by Patanjali.)

My ultimate digestion of this discomfort with the extraction of the asanas from the larger eight-limbed tradition of yoga may be reflected in the Buddhist adage: May a thousand flowers bloom. In other words: So what? Who cares? Why not? At least the annoying multitude of yogamat-toting (and sustainable-shopping-bag-toting) conformists, so to speak, is following that, instead of, say, following alcoholism, pugilism, fascism, or nihilism. And some of them are being drawn to traditional, full-fledged, eight-limbed yoga, thanks in no small part to the social acceptability of the popularized albeit watered down forms of yoga. There is probably some truth in the historical speculation to the effect that the yoga-mat swarm helped pave the way for the mindfulness swarm. Likewise, some of the folks constituting the mindfulness swarm are being drawn to traditional, full-fledged, Buddhist-eightfold-path-situated mindfulness, rather than being drawn to Ponzi schemes, religious fundamentalism, marijuana, or reality TV.

I may be guilty of confirmation bias, but one thing I feel fairly confident about is that many of the thousands of people I have taught meditation to, over the many years of my tenure as a Dharma teacher, yoga instructor, and philosophy professor, have learned something empowering and transformative: they have learned that they are capable of investigating their own minds and bodies - their intentions, emotions, bodily sensations, thoughts, beliefs, values, relationships, world views, life hopes, senses of self, hopes, fears, dreams, shadows, hatreds, judgments, and everything and anything else going on within them and without them-directly, personally, clearly, objectively. They have also learned that they can nurture themselves with the same compassion that they can lend to others, creating the conditions for their own healing, selfunderstanding, self-acceptance, and self-transformation. And they have learned that every moment is one in which mindfulness is the way to fully experience it, absorb it, digest it, and assimilate it, and mindlessness is the way to miss out on it, to fail to absorb, digest, or assimilate it. For most of the rest of them, I may be being naively optimistic, but I believe their meditation experiences function as slow-to-sprout seeds, if not effective inoculations against a variety of existential ills.

When asked once what he thought was the greatest thing about meditation in his life after all these years of promoting it, Ram Dass said that its value was best seen in its absence: during those times in his life that his practice lapsed he found himself walking around with a lot of undigested experiences. If mindfulness helps us digest experiences in this insanely unjust, 
information-overloaded world, then the complaint that it is a shortcoming of mindfulness that it fails to attempt to change an unjust world into a just one is analogous to the complaint that it is a shortcoming of antacids and probiotics that they fail to attempt to change an unjust world into a just one. Antacids and probiotics help us digest food; mindfulness helps us digest life.

I think we have sufficiently dispensed with the complaint to the effect that it is a shortcoming of mindfulness that it fails to attempt to change an unjust world into a just one. Let us turn, then, to the complaint to the effect that meditation plays less of a role in Buddhism than is commonly thought among Westerners, and thus is not as important to experts on it as we neophyte enthusiasts would like to think it is. Another, perhaps more exaggerated and unkind, way of expressing this complaint is to say-with a subtle but smug smirk - that you meditation newbies are making more of it than even the authoritative cognoscenti make of it, you are naively misguided, and your sought-after equanimity is adolescent, so knock it off already!

\section{Flanagan and Thompson}

Owen Flanagan ${ }^{29}$ and Evan Thompson ${ }^{30}$ each have claimed that meditation does not really matter to Buddhism the way Westerners have imagined it does, and that relatively few Buddhists actually meditate on a serious basis, as if the latter claim is evidence of the former. As Thompson put it, "Buddhism isn't reducible to meditation—most Buddhists throughout history haven't practiced sitting meditation." ${ }^{31}$ I do not want to give any false impressions about these otherwise brilliant philosophers, so it should be made clear that they are not really rejecting meditation so much as they are responding to its becoming a fetish among both Western practitioners of mindfulness and neuroscientists who might be thought to be testing Buddhism in the lab, as if meditating brains hold the keys to understanding Buddhism. But as valid as these intentions are, and I share them for the most part, this sort of claim itself - that meditation is not widely practiced among Buddhists, and the associated implication that it doesn't matter that much to Buddhism - still captures my interest the most, perhaps because I have made my own meditation practice the centerpiece of my philosophical life for over 40 years now. I may therefore be biased in my motivations, but that ought not to affect the validity of my argument.

Although Flanagan makes the same claim as Thompson about the small number of meditation practitioners in Buddhism, he also tries to hedge against its implication to the effect that meditation doesn't matter that much in Buddhism by arguing that it only matters that some meditation practitioners become virtuosos and thus instantiate, evidence, and validate those Buddhist claims that revolve around meditation. Fair enough, per se. In light of these and their other sympathetic concerns with meditation, perhaps it is not entirely accurate to saddle either

\footnotetext{
${ }^{29}$ Flanagan (2012).

${ }^{30}$ Heuman (2014).

${ }^{31}$ Heuman (2014).
} 
Flanagan or Thompson with the claim that I want to rebut, to the effect that because few Buddhists practice meditation it doesn't really matter that much to Buddhism, so I will simply assess that claim on its own, independently of whether this or that individual (or anyone, for that matter) wants to defend it, although some individuals clearly do hold the claim. ${ }^{32}$

I think one analogy alone ought to put an end to the sort of objection to the effect that meditation doesn't really matter even to the traditions that have brought it into great focus, as evidenced by its relatively small number of serious practitioners. Thus, consider this analogous argument:

Few Westerners participate in the practice of scholarly philosophy or scientific research on a regular basis - far less than one percent of the Western population throughout the history of Western society. Thus, philosophy and science do not really matter much, even within the traditions that brought them into great focus.

Hopefully, the fallacious nature of this analogous claim ought to be self-evident, but in case it is not, let us examine it some, in order to render its fallacious nature as perspicuous as possible.

Thus, the mere fact that less than, say, one percent of Westerners now and throughout Western history are or were actually practicing philosophers or scientists surely does not entail that philosophy and science are unimportant in current or earlier periods of Western society. To the contrary, though philosophers and scientists constitute a handful of people relative to the larger population, it is undeniable even that a very small, fractional subset of those philosophers and scientists that do or have practiced their crafts have had a tremendous impact on Western society. Take Plato, Aristotle, Copernicus, Newton, Bacon, Descartes, Darwin, Einstein, and Marx, to name just a few scientists and/or philosophers who have had monumental impact. Does the small percentage of practicing philosophers and scientists undermine the validity or importance of philosophy or science? The idea that it does is absurd.

If the scientific method and philosophical analysis became all the rage, so to speak, in Buddhist societies the way mindfulness has become all the rage in Western society, the parallel objection to the effect that the scientific method and analytic philosophy are not even all that important or widely practiced in the traditions that birthed and gave prominence to the scientific method and analytic philosophy would be as obviously absurd as the objection to Westerners embracing mindfulness to the effect that mindfulness doesn't really matter much or wind up actually being practiced much among Buddhists. But we need not wait for that reversal to happen to see the absurdity of this objection to mindfulness.

Yes, some folks are over-zealous, and others are over-emphasizing and perhaps hastily embracing overly confident interpretations of the powers and applications of mindfulness. And

\footnotetext{
32 At the NEH 2012 Summer Institute, "Investigating Consciousness: Buddhist and Contemporary Philosophical Perspectives," several philosophers and scholars expressed support for some version or another of this claim.
} 
yes, that bothers some Buddhists the way that the popularity of espresso and latte in Starbuck's might bother some Italians. But so what? Buddhists — of all people —ought to be able to deal with being bothered by such things. And, just as the objection about mindful Ninjas is rightly about Ninjas and not about mindfulness, so too the objection here is rightly about exaggerators and not about mindfulness.

\section{Conclusion}

In closing, I should make clear that I respect the otherwise insightful analyses, and I appreciate all the concerns, that the thinkers examined here have expressed about issues connected with meditation, apart from those specific aspects of their claims that I have rejected. I reiterate that my objections are restricted to these rather narrow features of their claims. Indeed, some of these critics are respected colleagues, personal friends, or both. My target has been simply to defend meditation against the four basic objections to the effect that it doesn't work, doesn't change the world, matters negatively, or doesn't matter.

In conclusion, while non-interfering meditation may be impossible in some cases, it is not impossible in all, but even when it is impossible it is the interfering that makes meditation effective, contra Ryle, and that shows it is not merely a damping down of our cognitive equipment, contra Nozick, but also something that strengthens our ability to regulate our volitions. Mindfulness can increase the disposition to altruistic engagement, rather than a retreat from unpleasant aspects of reality, contra Moore, Ginsberg, and Žižek. The independence of mindfulness from Buddhism's ethical framework is natural and desirable for various reasons, contra Sharf, Purser and Loy, Bodhi, and Forbes. The problems of meditation and $x$, so to speak, are problems of $x$, not of meditation, per se. And meditation matters, despite how few serious practitioners there are or have been, contra Flanagan and Thompson, within or outside Buddhism.

The opposite of mindlessness is as natural as is mindlessness, but unfortunately not as ubiquitous, and therefore its introduction into almost every conceivable venue in which mindlessness is the norm is at least as important as is the ubiquity of mindlessness - and therefore actually promises to be world-changing at the grass roots level. It is intuitively desirable in almost every conceivable case in which mindlessness is not desirable, just as the opposites of stupidity or of uncritical thinking are intuitively desirable in almost every conceivable case in which stupidity and uncritical thinking are not desirable. Of course, there are exceptions, but those are, by definition, exceptional.

Mindfulness matters, I conclude, most especially and significantly to those who do actually practice it seriously, who experience its impact directly, and thus who know its power, validity, and import in and over the course of their lives. And it matters to all of those who are close to them, whose lives are touched by them, whether they realize it or not. Every act of 
kindness, for example, even a friendly gesture toward a stranger, prompted by mindfulness, contributes to the common good. The amount of selfish competitiveness, insensitivity, judgmentalism, arrogance, aggression, and violence that would be emanating from me and that would have emanated from me over the course of my life had I not been practicing meditation for over 40 years certainly counts in the equation to assess the effectiveness of the practice and the extent to which it contributes to the common good or tends towards changing the world for the better, and I am but one person.

This article was not written so much on behalf of those who know all of this from their years on and off the meditation cushion as it was written on behalf of those who do not know any of this from firsthand experience, that is, for those who are, in a sense, mindless regarding the negative powers of mindlessness and the positive powers and importance of mindfulness. In light of all these points, it is incredible that otherwise really smart folks should be lamenting the explosion of interest in mindfulness. Imagine the horror of a world in which nearly everyone spent significant time cultivating mindfulness!

\section{References}

Bodhi, Bhikkhu. "What Does Mindfulness Really Mean? A Canonical Perspective," Contemporary Buddhism: An Interdisciplinary Journal 12:1 (2011), 19-39.

Davis, Jake H. and Evan Thompson. "Developing Attention and Decreasing Affective Bias: Toward a Cross-Cultural Cognitive Science of Mindfulness." In Handbook of Mindfulness, edited by K.W. Brown, J.D. Creswell, and R.M. Ryan. New York: Guilford Press (2015), 42-62.

Flanagan, Owen. The Bodhisattva's Brain: Buddhism Naturalized. Cambridge, MA: MIT Press, 2012.

Forbes, David. “Occupy Mindfulness,” Beams and Struts. June 30, 2012. URL:

http://beamsandstruts.com/articles/item/982-occupy-mindfulness (accessed August 6, 2014).

Frankfurt, Harry. "Freedom of the Will and the Concept of a Person," Journal of Philosophy 68:1 (1971), 5-20.

Goleman, Daniel. Varieties of the Meditative Experience. New York: E.P. Dutton, 1988.

Graziano, Michael S.A. Consciousness and the Social Brain. New York: Oxford University Press, 2013.

Hacking, Ian. Representing and Intervening: Introductory Topics in the Philosophy of Natural Science. Cambridge: Cambridge University Press, 1983.

Hampshire, Stuart. Freedom of the Individual. Princeton: Princeton University Press, 1975. 
Heuman, Linda. "The Embodied Mind: An Interview with Evan Thompson," Tricycle. Fall 2014. URL: http:/www.tricycle.com/interview/embodied-mind (accessed August 6, 2014).

Locke, John. An Essay Concerning Human Understanding (A.C. Fraser edition). New York: Dover, 1959.

Lutz, Antoine, Julie Brefczynski-Lewis, Tom Johnstone, Richard J. Davidson. "Regulation of the Neural Circuitry of Emotion by Compassion Meditation: Effects of Meditative Expertise," PLoS ONE (2008), 1-10.

Lutz, Antoine, Heleen A. Slagter, John D. Dunne and Richard J. Davidson. "Attention Regulation and Monitoring in Meditation," Trends in Cognitive Sciences 12 (2008), 163-169.

Moore, Suzanne. "Mindfulness Is All about Self-Help. It Does Nothing to Change an Unjust World," The Guardian (August 6, 2014). URL:

http://www.theguardian.com/commentisfree/2014/aug/06/mindfulness-is-self-help-nothing-tochange-unjust-world (accessed August 7, 2014).

Nozick, Robert. Philosophical Explanations. Cambridge, MA: Harvard University Press, 1981.

Perls, Fritz. Ego, Hunger, and Aggression. New York: Vintage, 1947.

Purser, Ron and David Loy. "Beyond McMindfulness," Huffington Post. July 1, 2013. URL: http://www.huffingtonpost.com/ron-purser/beyond-mcmindfulness b 3519289.html (accessed August 6, 2014).

Repetti, Riccardo. "Meditation and Mental Freedom: A Buddhist Theory of Free Will," Journal of Buddhist Ethics 17 (2010), 166-212.

Ryle, Gilbert. The Concept of Mind. Chicago, IL: University of Chicago Press, 1949.

Sharf, Robert H. "Varieties of Mindfulness. Mindfulness or Mindlessness: Traditional and Modern Buddhist Critiques of 'Bare Awareness."' Lecture, Advanced Study Institute, McGill University. June 3-5, 2012. URL: https://www.youtube.com/watch?v=c6Avs5iwACs (accessed August 6, 2014).

Thompson, Evan. Waking, Dreaming, Being: Self and Consciousness in Neuroscience, Meditation, and Philosophy. New York: Columbia University Press, 2014.

Waller, Bruce. "The Stubborn Illusion of Moral Responsibility.” In Exploring the Illusion of Free Will and Moral Responsibility, edited by Gregg D. Caruso, 65-86. Lanham, MD: Lexington Books, 2013.

Wolf, Susan. Freedom within Reason. New York: Oxford University Press, 1990. 
Žižek, Slavoj. "The Buddhist Ethic and the Spirit of Global Capitalism.” Lecture, European Graduate School. August 10, 2012. URL: http://www.egs.edu/faculty/slavoj-zizek/articles/thebuddhist-ethic-and-the-spirit-of-global-capitalism/ (accessed August 6, 2014). 